\title{
Mass spectra analysis of quinoline alkaloids detected in Sauuda fruticose leads to novel biosynthesis pathway of quinoline alkaloids
}

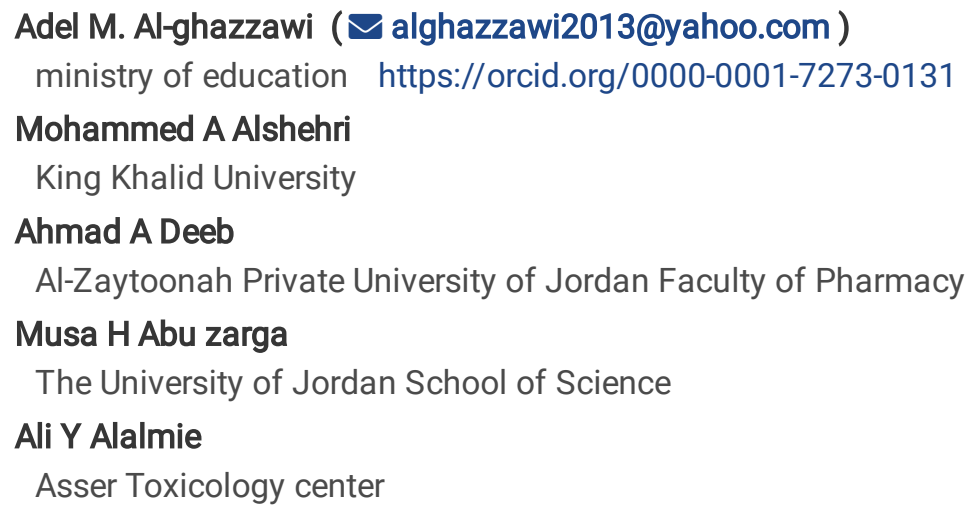




\section{Abstract}

Alkaloids reported to have a wide range of biological activity moreover, the biological effects of alkaloids depends on the type of the alkaloids and since the phytochemical screening studies on Suaeda fruticosa indicates the presence of alkaloids but they did not determine the types of the alkaloids present on this plant. Consequently, the LC-MS/MS analysis of the alkaloidal part of Suaeda fruticosa leave extarct reveals the presence of six quinoline alkaloids beside that mass spectra analysis of the present quinoline alkaloids leads to suggest a new biosynthetic pathway of quinoline alkaloids.

\section{1.introduction}

The coastal area of Saudi Arabia is rich in halophytes. One of these halophytes is Suaeda fruticosa which belongs to the Chenopodiaceae family and represents 23 genera one of them is suaeda genus. Six species of suaeda genus are found in Saudi Arabia(Alfarhan et. al. 2015; Nouri et. al. 2017; Oueslati et. al.2012 and Petropoulos et. al.2018)

Suaeda fruticosa is a shrub or small tree 1-2 m tall. The leaves are linear, glabrous, succulent, green, up to $2.5 \mathrm{~cm}$ long, $1-2 \mathrm{~mm}$ wide, and flattened on both sides. Flowers are in axillary clusters, sessile, small, and unisexual. Perianth fleshy is up to $1 \mathrm{~mm}$ long. Male flowers are larger than female flowers(Alfarhan et. al. 2015).

The phytochemical screening of Suaeda fruticosa indicates the presence of phenolics, flavonoids, tannins, alkaloids, saponins, proanthocyanins and carotenes(Mzoughi et. al. 2018 and Qasim et. al. 2017). Alkaloids are one of natural product classes present in Suaeda fruticosa which may have a good biological activity(Debnath et. al. 2018).Unfortionatelly, there is no study which describes the isolation and charaterization of alkaloids in Suaeda fruticosa.

Also the type of alkaloids present in Suaeda fruticosa is still unknown. The most important alkaloid type for the treatment of subtropical area diseases is quinoline alkaloids(Shang et. al. 2018 and Debnath et. al. 2018).

Quinoline alkaloids have attention from early times since the isolation of quinine from the bark of the Cinchona tree in 1820, which is used for malaria treatment(Shang et. al. 2018 and Debnath et. al. 2018).Quinoline alkaloids have a wide biological activity spectrum such as anti-malaria and anti-cancer applications(Nainwal et. al. 2019). Quinoline alkaloids can be divided into several subgroups according to their chemical structure but our focus here will be on simple quinoline alkaloids which consist of benzene ring fused with pyridine ring and different substitution patterns(Solomon et. al. 2011). There are two reported boisynthetic pathways for simple quinoline alkaloids: the first one is through anthralic acid and the other one is through tryptophane(Mann, 2005; de Souza et. al. 2003 and Sultana, 2013).

In this study LC-ESI-QTOF-MS/MS was used to analyse quinoline alkaloids in Suaeda fruticosa . In addition, the quinoline alkaloids biosythetic pathway was described.

\section{Results}

The LC-ESI-QTOF-MS/MS analysis of the alkaloidal part of Suaeda fruticosa extract revealed the presence of six oxygenated simple quinoline alkaloids (Fig. 1). The qualitative and quantitative analysis data for quinoline alkaloids in dry plants are described in table 1.

Table1: retention time, name of quinoline alkaloids, molecular mass found and calculated, main mass fragments, mass error in ppm, uncertainty in mass found, concntration of compounds in extratc and concentration of compounds in dry plants 


\begin{tabular}{|c|c|c|c|c|c|c|c|c|c|c|}
\hline $\mathrm{rt}$ & $\begin{array}{l}\text { Compound } \\
\text { Name }\end{array}$ & $\begin{array}{l}\text { Compound } \\
\text { formula }\end{array}$ & $\begin{array}{l}(\mathrm{M}+\mathrm{H}) \\
\text { found } \\
\text { from ms }\end{array}$ & $\begin{array}{l}(\mathrm{M}+\mathrm{H}) \text { found for } \mathrm{ms} / \mathrm{ms} \text {, } \\
\text { Intensity (\%) }\end{array}$ & $\begin{array}{l}(\mathrm{M}+\mathrm{H}) \\
\text { Calculated }\end{array}$ & $\begin{array}{l}\text { Mass } \\
\text { error } \\
\text { (ppm) }\end{array}$ & $\begin{array}{l}\text { Uncertainty } \\
\text { in } \mathrm{m} / \mathrm{z}\end{array}$ & $\begin{array}{l}\text { Conc. Of } \\
\text { compound } \\
\text { in extract } \\
\text { (ppm) }\end{array}$ & $\begin{array}{l}\text { Conc. Of } \\
\text { compound } \\
\text { in dry } \\
\text { plant } \\
\text { (ppm) }\end{array}$ & ref \\
\hline 1.64 & 3-hydroxyquinoline & $\mathrm{C}_{9} \mathrm{H}_{7} \mathrm{NO}$ & 146.0602 & $\begin{array}{l}146.0602(100 \%), \\
128.0497(5 \%), 117.0574(10 \%), \\
104.0484(7 \%), 91.0548(50 \%), \\
77.0392(50 \%)\end{array}$ & 146.0611 & -6.1618 & \pm 0.0009 & 934.5 & 5.4 & $\begin{array}{l}\text { Felczak } \\
\text { et. } \\
\text { al. } 2016\end{array}$ \\
\hline 1.83 & 6-Hydroxyquinoline & $\mathrm{C}_{9} \mathrm{H}_{7} \mathrm{NO}$ & 146.0602 & $\begin{array}{l}146.0602(100 \%), \\
128.0520(10 \%), 118.0635(10 \%) \\
, 91.0543(75 \%), 77.0388(50 \%)\end{array}$ & 146.0611 & -6.1618 & \pm 0.0009 & 224.6 & 1.3 & \\
\hline 5.64 & $\begin{array}{l}\text { 3-hydroxy-2- } \\
\text { quinolinone }\end{array}$ & $\mathrm{C}_{9} \mathrm{H}_{7} \mathrm{NO}_{2}$ & 162.0550 & $\begin{array}{l}162.0550(10 \%), \\
147.0462(10 \%), \\
144.0443(30 \%), \\
118.0660(80 \%), \\
116.0506(100 \%), \\
91.0535(60 \%), 89.0379(30 \%), \\
79.0544(25 \%)\end{array}$ & 162.0561 & -6.1707 & \pm 0.0010 & & & \\
\hline 5.31 & Quinoline-2,3-oxide & $\mathrm{C}_{9} \mathrm{H}_{5} \mathrm{NO}$ & 144.0451 & $\begin{array}{l}144.0451(60 \%) \\
116.0497(80 \%), 89.0388(100 \%)\end{array}$ & 144.0455 & -2.7769 & \pm 0.0004 & & & \\
\hline 5.31 & $\begin{array}{l}\text { 3-Hydroxy-2- } \\
\text { methoxyquinoline }\end{array}$ & $\mathrm{C}_{10} \mathrm{H}_{9} \mathrm{NO}_{2}$ & 176.0706 & $\begin{array}{l}\text { 176.0706( } 20 \%), 158.0609, \\
(10 \%), \\
144.0456,(100 \%), \\
119.0783(10 \%), 117.0575(60 \%), \\
116.0494(80 \%), 106.0727(5 \%), \\
89.0387,60 \% .\end{array}$ & 176.0717 & -6.2475 & \pm 0.0011 & 48.5 & 0.3 & \\
\hline 5.65 & $\begin{array}{l}2,3- \\
\text { Dimethoxyquinoline }\end{array}$ & $\mathrm{C}_{11} \mathrm{H}_{11} \mathrm{NO}_{2}$ & 190.0863 & $\begin{array}{l}162.0552(10 \%), \\
144.0450(60 \%), \\
118.0652(100 \%) \\
117.0575(38 \%) \\
116.0487(40 \%), \\
91.0540(100 \%), 89.0391(35 \%)\end{array}$ & 190.0874 & -5.7868 & \pm 0.0011 & 132.9 & 0.8 & \\
\hline
\end{tabular}

Also, mass spectra analysis of the detected quinoline alkaloids leads to suggest a new biosynthetic pathway(scheme 1 and 2 ).

Table 2: LC gradient parameters

\begin{tabular}{cccc}
\hline Time(min) & Flow Rate (mL/min & A Conc. & B Conc. \\
\hline $\mathbf{0 0 . 0}$ & 0.7 & 90.0 & 10.0 \\
\hline $\mathbf{7 . 0 0}$ & 0.7 & 2.00 & 98.0 \\
\hline $\mathbf{8 . 5 0}$ & 0.7 & 2.00 & 98.0 \\
\hline $\mathbf{8 . 6 0}$ & 0.7 & 90 & 10.0 \\
\hline $\mathbf{9 . 5 0}$ & \multicolumn{4}{c}{} \\
\hline
\end{tabular}

\section{Discussion}

\subsection{Mass spectra analysis of detected quinoline alkaloids:}

Two types of oxygenated quinoline alkaloids were detected in Suaeda fruticosa extract. One is oxygenated in one position while the other is oxygenated in two positions.

\subsubsection{Mass spectra analysis of quinoline alkaloids oxygenated at one possiton:}

From this type two quinoline alkaloids were detected. 3-hydroxyquinoline (1) and 6-hydroxyquinoline (2). Their mass spectra (Fig. 2) illustrated a similarity and the only difference was the relative intensity of M-28 peak and this exclude the probapility of 2,4 and 8 oxygenated quinoline[15]. 
Also, M-55 peak appeared at high intensity compared with 5 and 7 oxygenated quinoline, so the possible oxygenation positions are 3 and 6(Kaczmarek and Steinegger, 1958). The difference between 3-hydroxy and 6-hydroxy is the presence of mass peak at 104.0484 which indicates the loss of $\mathrm{H}_{2} \mathrm{O}$ followed by loss of $\mathrm{C} 2$. This is only possible for 3-hydroxyquinoline. Also, the retention time indicates a very low difference in polarity between the two compounds, therefeore 3-hydroxy is more polar than 6-hydroxy. The mass fragmentation pattern of the two compounds was given in Fig. 3.

\subsubsection{Mass spectra analysis of quinoline alkaloids oxygenated at two possitons:}

Four quinoline alkaloids were detected to be oxygenated at two positions but the only two possible positions were 2 and 3 . Fig. 4 represents the mass spectra of the four compounds. The main peaks in all compounds are 144.0450, 116.0494 and 89.0387 Figure 5 shows the structure of these peaks and how they are formed .On other hand, the chvracterestic fragmentation in compounds 3 and 5 was due to the loss of $\mathrm{H}_{2} \mathrm{O}[\mathrm{M}-18]$ and this indicates the presence of hydroxyl group in both compounds. In addition, some charcterstic peaks were found to prove the position of substituents.

For compound 3 , three charcterstic peaks proved the porposed structure of the compound. The first peak appeared at $\mathrm{m} / \mathrm{z}=$ 147.0462 which results from NH loss and this indicates an amid group in the compound. The other peaks at $\mathrm{m} / \mathrm{z}=118.0660$ and $\mathrm{m} / \mathrm{z}=91.0555$ indicate the presence of a-hydroxy to carbonyl group.

In compound 5, the appearance of two peaks at $\mathrm{m} / \mathrm{z}=119.0783$ and 106.0727 gives an evidance for the porposed strcture as explained in fig. 6 .

Two main peaks proving the proposed structure for compound 6 . The first one $\left[M-\mathrm{C}_{2} \mathrm{H}_{4}\right]$ at $\mathrm{m} / \mathrm{z}=162.0552$ indicates that the two methoxy groups are adjacent and this peak was followed by the loss of $\mathrm{CO}_{2}$ to give a peak at $\mathrm{m} / \mathrm{z}=118.0652$ like compound 3 , after that the loss of $\mathrm{HCN}$. The other peak at $\mathrm{m} / \mathrm{z}=146.0937$ which due to $\left[\mathrm{M}-\mathrm{CO}_{2}\right]$ reveals a methoxy group at position 2 to allow rearrangement and the loss of $\mathrm{CO}_{2}$ as described in Fig. 7 .

\subsection{Biosynthetic pathway for the detected quinoline alkaloids}

LC-MS/MS analysis of Suaeda fruticosa showed the presence of quinoline alkaloids, anthranilic acid and indole and the absence of tryptophane. Moreover, all detected quinoline alkaloids do not have hydroxyl group at position 4 which indicats that the biosynthetic pathway of quinoline alkaloids in Suaeda fruticosa is different from the reported one in other plants. The presence of 3-

hydroxyquinoline and indole supports the hypothesis of sugested biosynthetic pathway shown in schem 1 . Since this pathway was reported for indol, the only difference is in the cyclization mechanism in the last step in indole to give 5 memberd ring and 3phosphglyceraldehyde but in the suggested pathway gives 3-hydroxyquinoline and phosphoacetaldehyde.

Its noteworthy that 3-hydroxyquinoline is a precursore for all other quinoline alkaloids present in Suaeda fruticosa as shown in schem 2 and all steps are common steps in plants which include oxidation, hydration and methylation.

\section{Conclusion}

In this study six quinoline alkaloids were detected in the leaves of Suaeda fruticosa by using LC-MS/MS analysis beside that a new biosynthesis pathway for quinoline alkaloids were sugested in light of the component of leaves of Suaeda fruticosa.

\section{Materials And Methods}

All chemicals were purchased from Sigma-Aldrich.

\subsection{Plant material}

The fresh leaves of Suaeda fruticosa collected from Al- Berk beach at $(18.334391,41.463814)$ Asser region, Saudi Arabia on 21 July 2017. The plant material was identified in biology department of King Khalid University.

For crud extract preparation 200 grams of fresh leaves were washed with distilled water and dried in the shade for 15 days then ground via grinder. The powder was soaked in petroleum ether of 10 days for defatting then extracted thoroughly with ethanol four 
times each time needs 7 days later .

The ethanol extract was filtered using filter paper and concentrated to dryness under reduced pressure using a rotary evaporator at $37^{0} \mathrm{c}$ (Ikia -Germany). The concentrated crude extract weight $24 \mathrm{~g}$, which represent (6\%)of the plant weight.

\subsection{Preparation of alkaloidal extract}

The ethanol residue was dissolved in $5 \% \mathrm{HCl}$ until the $\mathrm{PH}=2$ of the solution and filtered, the precipitate which contains neutral material was kept for further fractionation, and the filtrate which provides the basicmaterial was basify using $\mathrm{NH} 4 \mathrm{OH}$ solution, and the $\mathrm{PH}$ of the solution becomes around 8. After that, the solution was extracted with chloroform $50 \mathrm{~mL}$ three times the chloroform layer was evaporated to get $0.246 \mathrm{~g}$ of crude alkaloids which represent $0.123 \%$ of the dry plant.

\subsection{LC-MS/MS for Plant Extracts}

Analyses were performed on SCIEX X500R QTOF system (includes UPLC-MS/MS (Woodlands Central Indus. Estate., Singapore)). The separation was performed using Phenomenex Kinetex 2.6_m Phenyl-Hexyl 100 A (50_ 4.6 mm, Phenomenex, Madrid Avenue, Torrance, CA, USA). The mobile phase consists of phase A (10 mM ammonium formate in water) and phase B (0.05\% formic acid in methanol). A variable gradient flow rate was used, which is described in Table 2. A positive non-targeted mode was used for the analyte.

Table 2: LC gradient parameters

\begin{tabular}{cccc}
\hline Time(min) & Flow Rate (mL/min & A Conc. & B Conc. \\
\hline $\mathbf{0 0 . 0}$ & 0.7 & 90.0 & 10.0 \\
\hline $\mathbf{7 . 0 0}$ & 0.7 & 2.00 & 98.0 \\
\hline $\mathbf{8 . 5 0}$ & 0.7 & 2.00 & 98.0 \\
\hline $\mathbf{8 . 6 0}$ & 0.7 & 90 & 10.0 \\
\hline $\mathbf{9 . 5 0}$ & \multicolumn{3}{c}{} \\
\hline
\end{tabular}

\section{Declarations}

\subsection{Ethics approval and consent to participate}

Not applicable

\subsection{Consent for publication}

Not applicable

\subsection{Availability of data and material}

The datasets used and/or analysed during the current study are available from the corresponding author on reasonable request.

\subsection{Competing interests}

The authors declare that they have no competing interests

\subsection{Funding}

Self-funded by the authors

6.6. Author Contribution: Experiments and the writing of the manuscript were carried out in contribution of all authors. All authors read and approved the final manuscript.

\subsection{Acknowledgements}

The author extend his appreciation to Dr. Kamel A. Saleh from Department of Biology, Science College, King Khalid University for his help in data analysis and editing the manuscript. 


\section{References}

1. Alfarhan, A. H., Al-Turki, T. A., \& Basahy, A. Y. 2005. Flora of Jizan region. Final Report Supported by King Abdulaziz City for Science and T; echnology, 1, 545

2. Debnath, B., Singh, W. S., Das, M., Goswami, S., Singh, M. K., Maiti, D., \& Manna, K. 2018. Role of plant alkaloids on human health: A review of biological activities. Materials Today Chemistry, 9, 56-72.

3. de Souza, M. V. N., de Almeida, M. V., Le Hyaric, M., Cardoso, S. H., \& Amarante, G. W. 2003. Métodos de preparação e atividade biológica do ácido quinolínico e derivados. Química Nova, 26(5), 694-698.

4. Felczak, A., Bernat, P., Różalska, S., \& Lisowska, K. (2016). Quinoline biodegradation by filamentous fungus Cunninghamella elegans and adaptive modifications of the fungal membrane composition. Environmental Science and Pollution Research, 23(9), 8872-8880.

5. Kaczmarek, F., and Steinegger, E. 1958. Chromatographic studies on the basic fractions of Lobella cardinalis, especially of lobinaline and the new cardinalis alkaloid 2. Pharmaceutica acta Helvetiae, 33(11-12), 852.

6. Mann, J. J. 2005. The medical management of depression. New England Journal of Medicine, 353(17), 1819-1834.

7. Mzoughi, Z., Abdelhamid, A., Rihouey, C., Le Cerf, D., Bouraoui, A., \& Majdoub, H. 2018. Optimized extraction of pectin-like polysaccharide from Suaeda fruticosa leaves: Characterization, antioxidant, anti-inflammatory and analgesic activities. Carbohydrate polymers, 185, 127-137.

8. Nainwal, L. M., Tasneem, S., Akhtar, W., Verma, G., Khan, M. F., Parvez, S., ... \& Alam, M. M. 2019. Green recipes to quinoline: a review. European journal of medicinal chemistry, 164, 121-170.

9. Nouri, H., Borujeni, S. C., Nirola, R., Hassanli, A., Beecham, S., Alaghmand, S., and Mulcahy, D. 2017. Application of green remediation on soil salinity treatment: A review on halophytoremediation. Process safety and environmental protection, 107, 94-107.

10. Oueslati, S., Ksouri, R., Falleh, H., Pichette, A., Abdelly, C., \& Legault, J. 2012. Phenolic content, antioxidant, anti-inflammatory and anticancer activities of the edible halophyte Suaeda fruticosa Forssk. Food Chemistry, 132(2), 943-947.

11. Petropoulos, S. A., Karkanis, A., Martins, N., \& Ferreira, I. C. 2018. Edible halophytes of the Mediterranean basin: Potential candidates for novel food products. Trends in food science \& technology, 74, 69-84.

12. Qasim, M., Abideen, Z., Adnan, M. Y., Gulzar, S., Gul, B., Rasheed, M., \& Khan, M. A. 2017. Antioxidant properties, phenolic composition, bioactive compounds and nutritive value of medicinal halophytes commonly used as herbal teas. South African Journal of Botany, 110, 240-250.

13. Shang, X. F., Morris-Natschke, S. L., Liu, Y. Q., Guo, X., Xu, X. S., Goto, M., ... \& Lee, K. H. 2018. Biologically active quinoline and quinazoline alkaloids part I. Medicinal research reviews, 38(3), 775-828.

14. Solomon, V., \& Lee, H. 2011. Quinoline as a privileged scaffold in cancer drug discovery. Current medicinal chemistry, 18(10), 1488-1508.

15. Sultana, N. 2013. Medicinal properties and biosynthetic studies on indigenous medicinal plant Skimmia laureola. Critical Review in Pharmaceutical Sciences, 2(2), 13-42.

\section{Schemes}

Scheme 1: Biosynthesis pathway of 3-hydroxyquinoline 
<smiles>Nc1ccccc1C(=O)O</smiles>

Anthranilic acid<smiles>Cc1cccc(C(=O)[O-])c1N</smiles>

Anthranilate

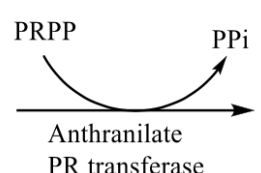

PR transferase<smiles>O=C(O)c1ccccc1NC1O[C@H](COP(=O)([O-])O)[C@@H](O)[C@H]1O</smiles>

Phosph oribosy 1 anthran ilate

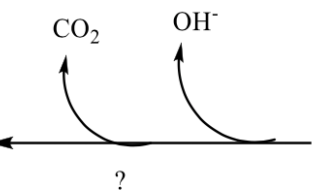<smiles>O=P(O)(O)O</smiles><smiles>Cc1c(O)cnc2ccccc12</smiles><smiles>CCC=O</smiles><smiles>c1ccc2ncccc2c1</smiles>

3-Hydroxyquinoline

Scheme 2: Biosynthesis pathway of compounds 3,4,5 and 6<smiles>Oc1cnc2ccccc2c1</smiles>

3-Hydroxyquinoline (1)<smiles>c1ccc2nc3c(cc2c1)O3</smiles>

Quinoline-2,3-oxide (4)<smiles>COc1nc2ccccc2cc1O</smiles>

3-Hydroxy-2-methoxyquinoline (5)

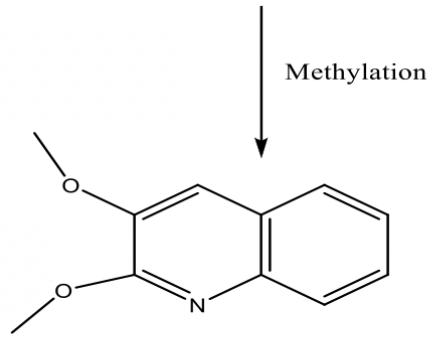

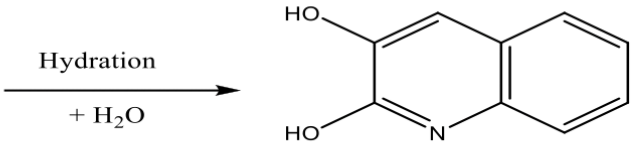

2,3-dihydroxyquinoline

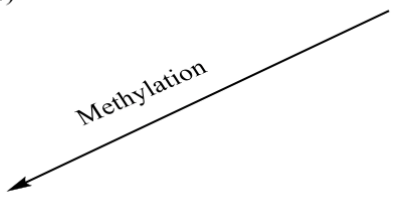

3-Hydroxy-2-quinolinone (3) 
Figures

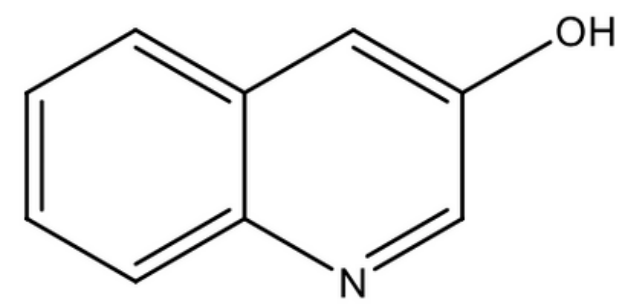

3-Hydroxyquinoline (1)

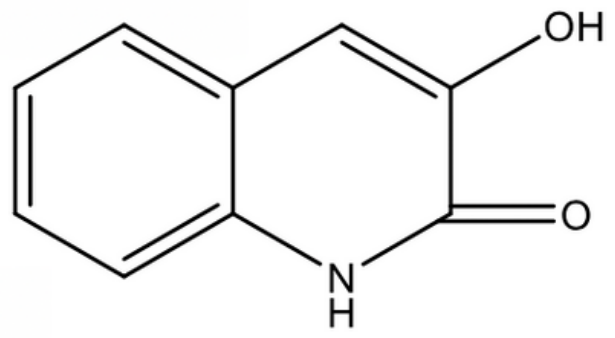

3-Hydroxy-2-quinolinone (3)

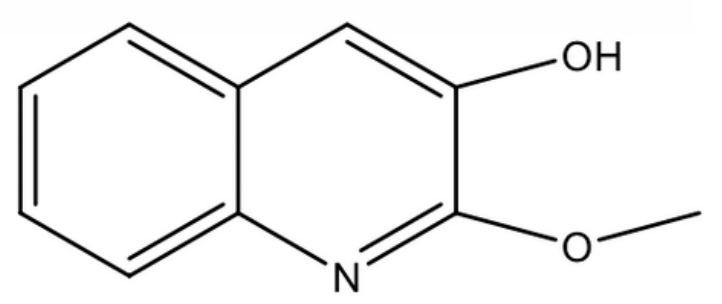

3-Hydroxy-2-methoxyquinoline (5)

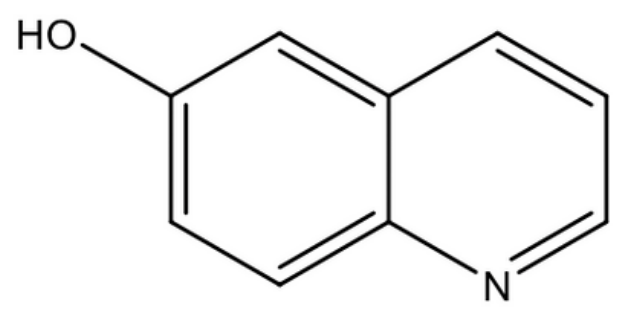

6-Hydroxyquinoline (2)

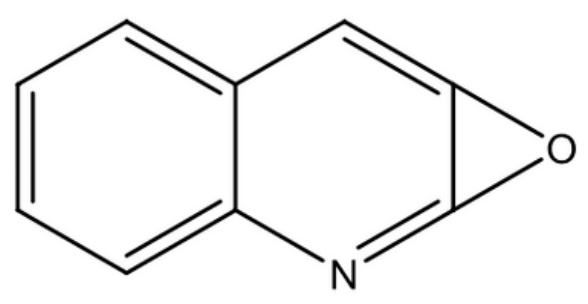

Quinoline-2,3-oxide (4)

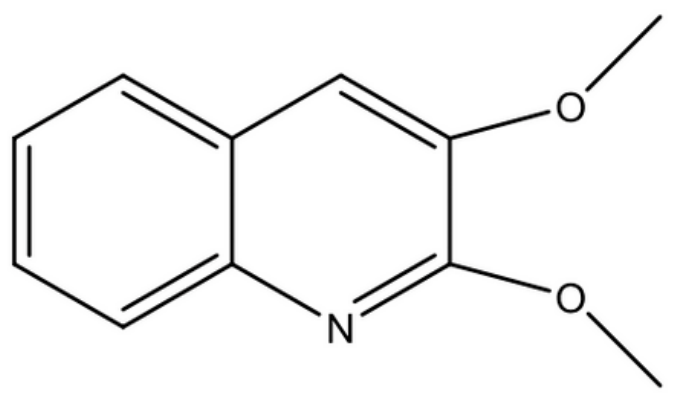

2,3-Dimethoxyquinoline (6)

\section{Figure 1}

Structures of detected oxygenated quinoline alkaloids

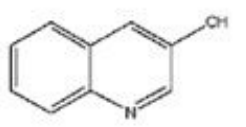

3.Hydroxyçumaline (1)

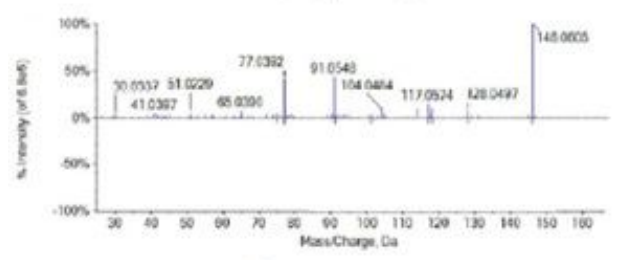

a

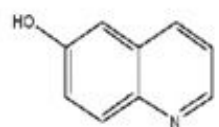

6.Hydruxquadure(2)

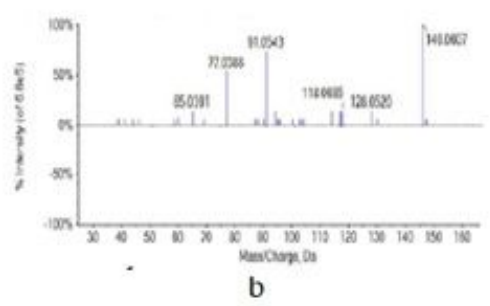


Figure 2

a) mass spectrum of 3-hydroxyquinoline (1) b) mass spectrum of 6-hydroxyquinoline
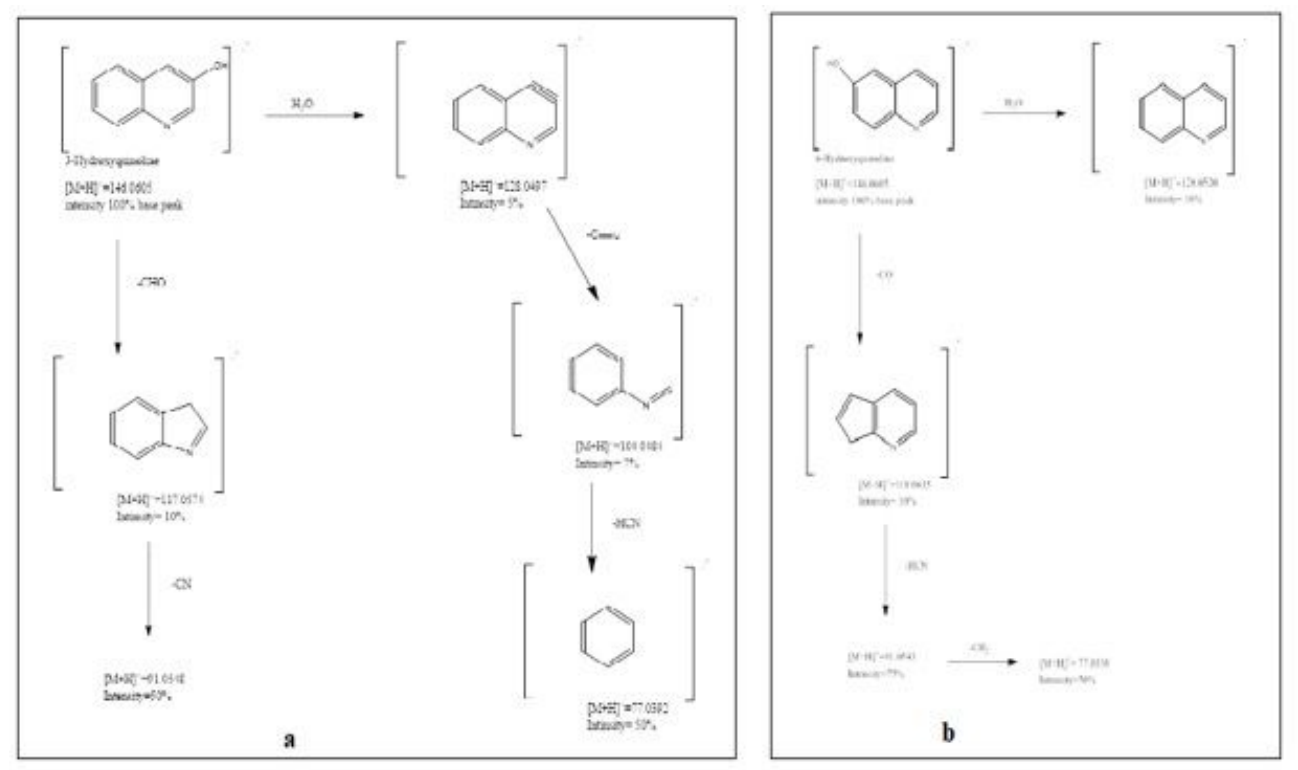

Figure 3

Mass fragmentation of a) 3-hydroxyquinoline (1) b) 6-hydroxyquinoline

a

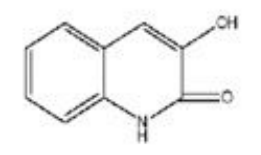

3. Hydtaxy-2-runenolinome (3)

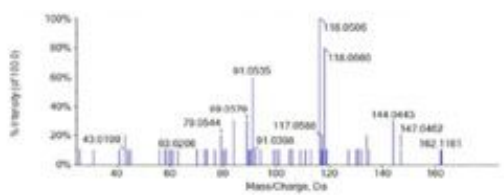

c

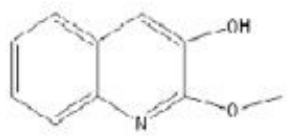

3.-Hydroxy-2-netiassyquancline (S)

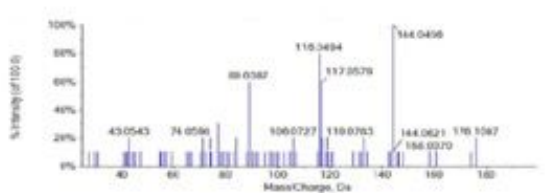

b

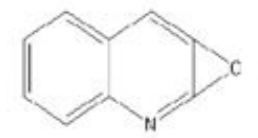

Quinolixe-2.3-oxide (4)

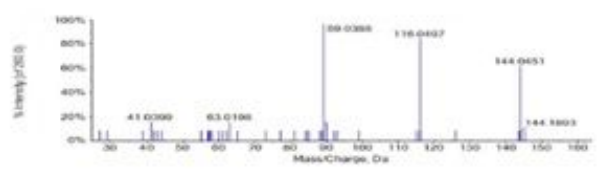

d

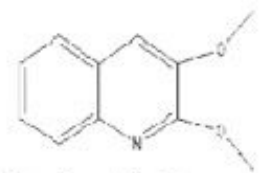

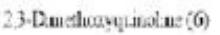

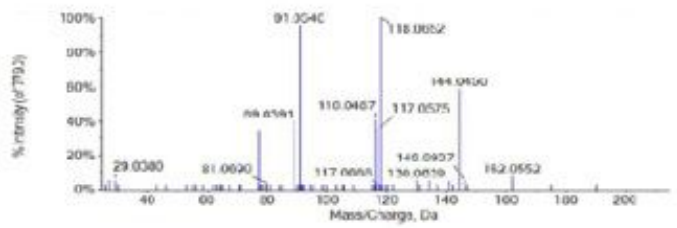

\section{Figure 4}

mass spectrum of a) 3-hydroxy-2-quinolinone (b) quinoline-2,3-oxide (c) 3-hydroxy-2-methoxyquinoline (d) 2,3-dimethoxyquinoline 


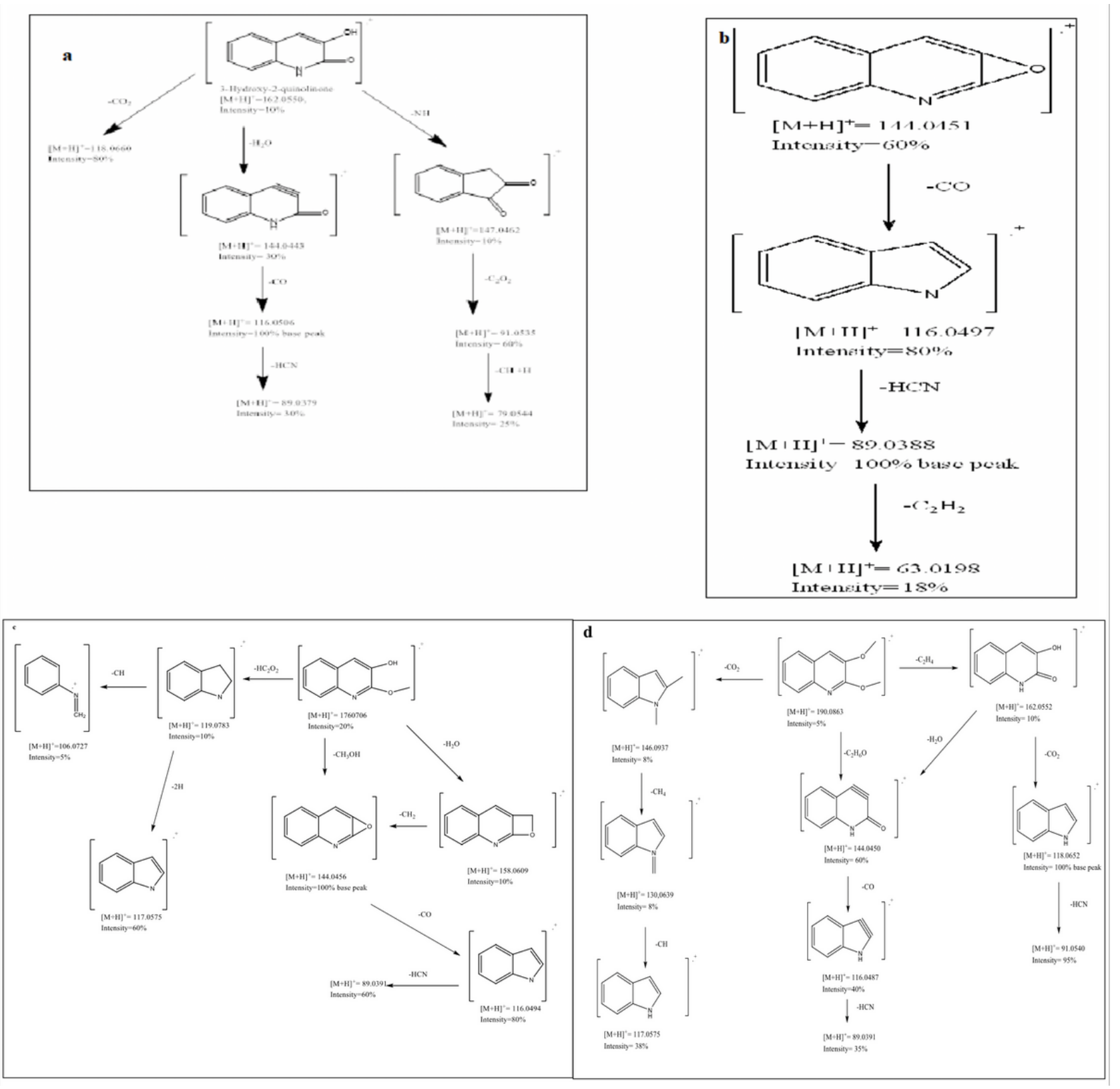

Figure 5

Mass fragmentation of a) 3-hydroxy-2-quinolinone (b) quinoline-2,3-oxide (c) 3-hydroxy-2-methoxyquinoline (d) 2,3dimethoxyquinoline 


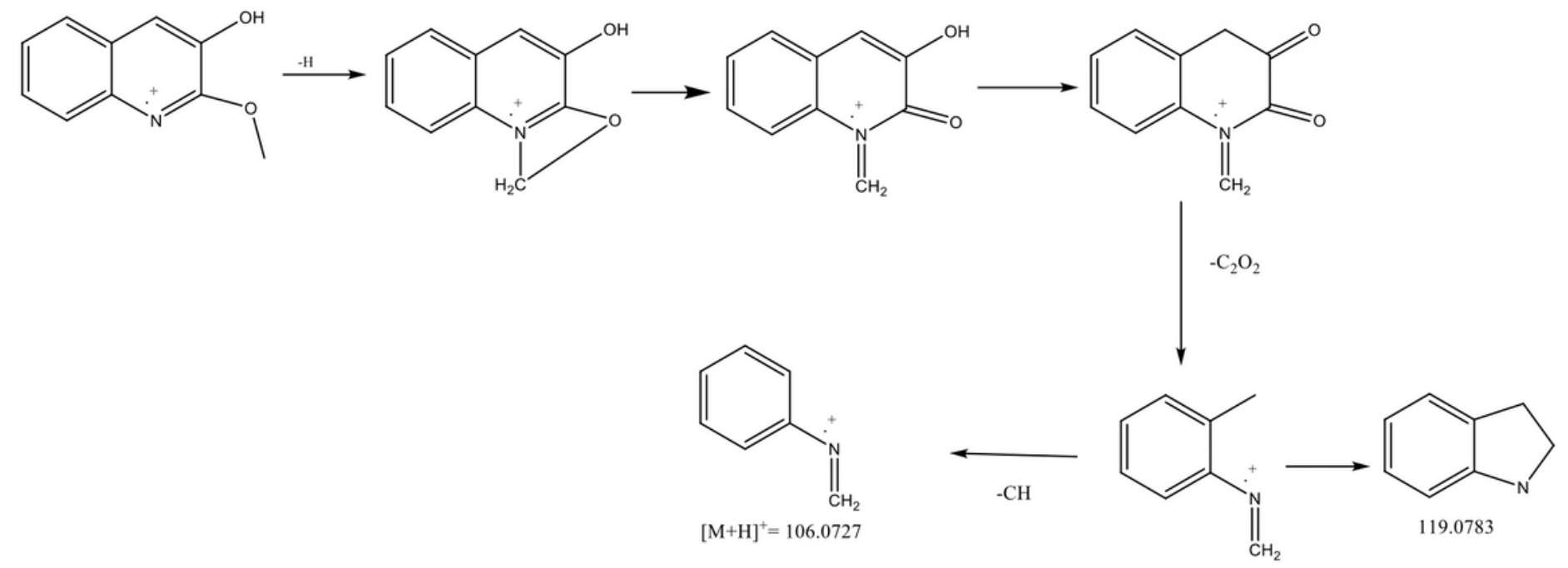

Figure 6

Rearengment in compound 5<smiles>COc1cc2ccccc2nc1OC</smiles>

Methyl group megration<smiles>Cc1ccc2c(c1)CCCO2</smiles><smiles>CC1=Cc2ccccc2N(C)C1(C)C(=O)O</smiles><smiles>c1ccc2[nH]ccc2c1</smiles>

$[\mathrm{M}+\mathrm{H}]^{+}=117.0575$
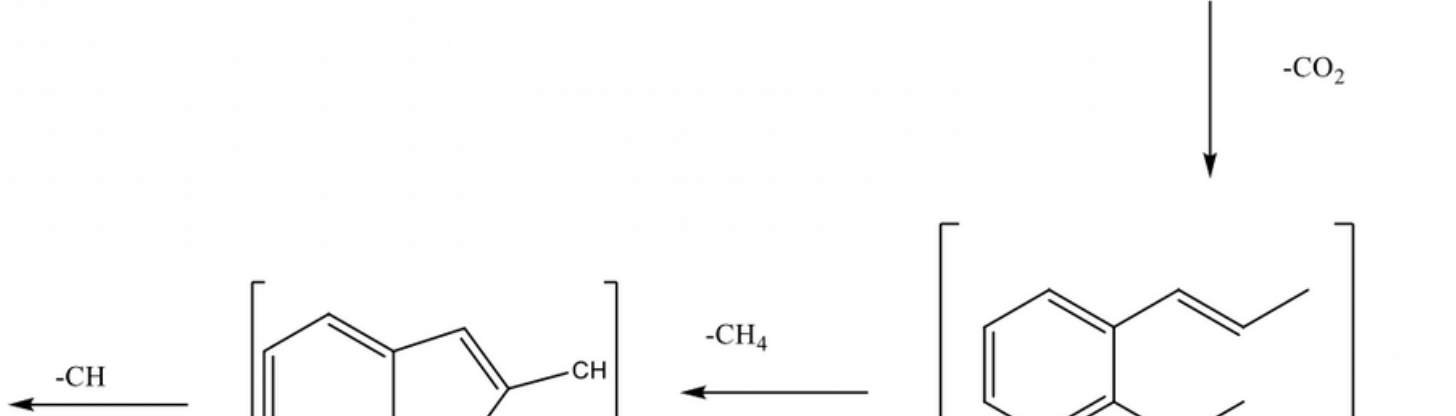<smiles>Cc1ccc2[nH]c(C)cc2c1</smiles>

$[\mathrm{M}+\mathrm{H}]^{+}=130.0639$

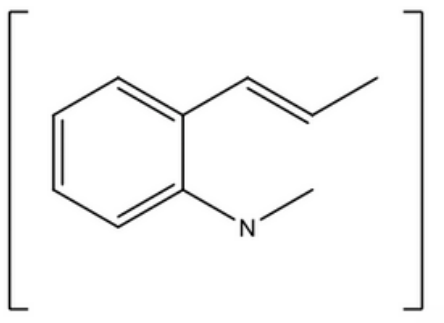

$[\mathrm{M}+\mathrm{H}]^{+}=146.0937$

Figure 7

Rearengment in compound 6 